\title{
INFLUENCE OF ORAL RINSE SOLUTIONS AND TOOTH BRUSHING ON STAIN ABILITY OF THERMOPLASTIC TOOTH COLORED PROSTHETIC MATERIALS
}

\author{
Azza A. El- Segai *, Zainab EL Sharkawy ${ }^{* *}$ and Muhammad Abbas ${ }^{* * *}$
}

\begin{abstract}
Objectives: The present study aimed to comparatively evaluate the influence of oral rinse solutions and tooth brushing on stainability of thermoplastic tooth colored prosthetic materials, using computerized spectrophotometry before and after immersion.

Materials and Methods: Fifty-six samples (Twenty-eight samples of each material); Acetal resin and polyether ether keton(PEEK) were constructed in the form of discs $(10 \mathrm{~mm}$ in diameter and $2 \mathrm{~mm}$ in thickness). Samples were randomly divided into 4 subgroups ( $\mathrm{n}=7$ ) according to the oral rise solutions (chlorhexidine, benzydamine $\mathrm{HCl}$, alcohol-free mouthwash) and artificial saliva as control. Simulated tooth brushing of samples for 4 min with rotary instruments was applied before immersion in mouth rinses. The mean of color values $\left(\mathrm{L}^{*}, \mathrm{a}^{*}, \mathrm{~b}^{*}\right)$ of each specimen were measured before and one week after exposure with a Reflective spectrophotometer.
\end{abstract}

Results: regardless to staining solutions totally it was shown that Acetal resin material group recorded higher color change mean value $(4.75 \pm 0.52 \Delta \mathrm{E})$ than PEEK material group mean value $(4.64 \pm 0.66 \Delta \mathrm{E})$.The difference between both materials groups means values was statistically nonsignificant as indicated by two-way ANOVA $(\mathrm{F}=0.31, \mathrm{P}=0.5748>0.05)$. On the other hand Listerine zero recorded the highest color change mean value $(5.05 \pm 0.5 \Delta \mathrm{E})$ followed by Tantum $\mathrm{V}$ solution mean value $(4.91 \pm 0.37 \Delta \mathrm{E})$ then $\mathrm{CHX}$ solution mean value $(4.52 \pm 0.7 \Delta \mathrm{E})$ while $\mathrm{A}$. saliva solution recorded the lowest color change mean value $(4.29 \pm 0.52 \Delta \mathrm{E})$.

Conclusions: 1 - There was a highly significant difference between alcohol free, benzydamine HCL \& CHX mouth rinses. The listerine zero showed the highest value in staining potential while CHX was the lowest regarding acetal 2- Among the two thermoplastic restorative materials and although statisticaly non significant, PEEK was found to be the higher color stable material and the higher stain was taken up by acetal resin. 3- There were no significant differences between the discoloration effects of different mouth washes used in this study on PEEK material.

* Assistant Professor, Removable Prosthodontics Department, Faculty of Dentistry, Tanta University, Egypt ** Lecturer, Crowns and Bridges Department, Faculty of Dental Medicine for Girls, Al Azhar University, Egypt *** Assistant Professor, Dental Biomaterials Department, Faculty of Dental medicine, Al-Azhar University, Egypt 


\section{INTRODUCTION}

Oral rehabilitation is critical regarding functional and esthetic outcomes. At first glance, the esthetic appearance of any restoration is of enormous subjective concern for both patient and oral care provider, in addition biocompatibility and function that considered as major aspects. ${ }^{1}$ Therefore, an adequate material choice and processing can guarantee longevity and patient satisfaction., ${ }^{2,3}$

On the basis of superior esthetics, navigation in polymer science has provided us with tooth colored substitute called "Acetal resin". It is a thermoplastic monomer-free crystalline structure. ${ }^{4}$ The homopolymer, Polyoxymethylene (POM) is a chain of alternating methyl groups linked by an oxygen molecule. This material has been believed to have good biocompatibility rationalizing its use in total hip replacement and as artificial valve occluders. ${ }^{4}$ In dental field, it has been used as provisional restorations, splints and to form a stress absorbing element in a dental implant system. ${ }^{5}$ Its use as denture base materials was first advocated by Smith $^{6}$ and subsequently marketed as alternative denture base and clasp material since 1986.

PEEK is relatively recent material in dentistry compared with composite, ceramics or zirconia. It is white, radiolucent, rigid material with reduced plaque affinity ${ }^{7-9}$ and flexural modulus $140-170 \mathrm{MPa}$. Several applications of PEEK in prosthodontics as implant abutments, permanent fixed crowns and bridges, removable dentures and components were reported by Najeeb et $\mathrm{al}^{7}$.

The degree of color change can be affected by a number of factors including: incomplete polymerization, water sorption, chemical reactivity, diet, oral hygiene, surface smoothness of material, cleaning measures and rinses. ${ }^{10,11}$ Discoloration of dental prostheses is measured as value developed over a specific period of time by a spectrophotometric technologies (e.g., CieLabSystem) which are widely used in dental color studies. ${ }^{12}$ The present study was designed using this technology to assess the effect of three different oral rinses (chlorhexidine, benzydamine $\mathrm{HCl}$, alcoholfree mouthwash), and artificial saliva on the color change property of Acetal resin compared to PEEK. The following two null hypotheses were formulated:

1- There is no difference in color change behavior of both acetal and PEEK materials among three oral rinses and artificial saliva used in this study

2- There is no difference in color change effect of three oral rinses and artificial saliva used in this study on both acetal and PEEK materials.

\section{MATERIALS AND METHODS}

Two thermoplastic materials (Acetal resin and PEEK), three staining solutions (chlorhexidine, benzydamine $\mathrm{HCl}$, alcohol-free mouthwash) and artificial saliva as control were used in this study. Fifty-six samples (Twenty-eight samples of each material); Acetal resin and PEEK were constructed in the form of discs $(10 \mathrm{~mm}$ in diameter and $2 \mathrm{~mm}$ in thickness) this sample configuration was selected because it fits the experimental system by allowing the medium to completely cover the samples. Also, it could be considered as a adequate thickness that would be present in prosthetic appliances. Samples were randomly divided into 4 subgroups according to the oral rise solutions $(n=7)$. Materials and staining solutions are listed in Table 1

\section{Acetal samples construction:}

The acetal resin (Thermoflex Acetal Resin Densply UK) samples were prepared in accordance with manufacturer's instructions. The pattern of the disc was made in wax (28 discs; $10 \mathrm{~mm}$ in diameter with thickness of $2 \mathrm{~mm}$ ) and flasked using special Aluminum flask (Thermopress flask, bredent $\mathrm{GmbH}$, Senden/ Witzighausen, Germany) mouldwith Class IV type plaster (Marble Stone, Pressing Dental San Marino, Italy). Heated softened acetal resin was injected into the mold then curing 
TABLE (1) Materials names, types and manufacturers used in the study

\begin{tabular}{|c|c|c|c|}
\hline Brand & Material type & Manufacturer & Lot \# \\
\hline Thermoflex Acetal Resin & Polyoxymethylene & Densply UK & 1065 \\
\hline PEEK-BioHPP & Polyetheretherketone & Bredent-Senden-Germany & $540 X S 016901$ \\
\hline Hexitol & Chlorhexidine HCL 125mg100/ ml & Arab drug company, Cairo, Egypt & 530330 \\
\hline Tantum Verde & Benzydamine HCL 0.15 g & EIPICO, under license of ACR & 1510794 \\
\hline Listerine zero & $\begin{array}{c}\text { A.064\%elini, Italy } \\
\text { methyl salicylate, 0.042\% menthol }\end{array}$ & Johnson and Johnson, Italy & 647960 \\
\hline
\end{tabular}

was done at $215 \mathrm{C}^{0}$ for 25 minutes and injection pressure of 4 bar. After curing the samples were deflasked, finished and polished using thermal resin finishing burs (Abraso-Star K 50, bredent $\mathrm{GmbH}$, Senden/Witzighausen. Germany) and pumice at low speed then finally buffed with swans down mop for fine luster.

For all samples one surface was polished and the other one was only finished without polishing to resemble both the fitting and polished surface.

\section{PEEK samples construction:}

Wax patterns of 28 discs $(10 \mathrm{~mm}$ in diameter with thickness of $2 \mathrm{~mm}$ ) were constructed and sprues were attached. The assembly was attached to the investment ring then invested using special investment material Brevest for 2 press (BredentSenden-Germany), after material setting the mould was then heated to $630^{\circ} \mathrm{C}$ then temperature was gradually increased by rate of $8^{\circ} \mathrm{C} / \mathrm{min}$ until it reached $850^{\circ} \mathrm{C}$ in a preheated oven (IBEX-dental oven-USA) for wax burnout for 60 minutes before starting the melting process. Granular PEEKBioHPP thermoplastic (BioHPP (granulate) 20g-Bredent-Senden-Germany) material was placed in the melting channel. Then the ring was placed back into the preheated oven for 20 minutes at temperature $400^{\circ} \mathrm{C}$ to get a creamy molten material with uniform appearance indicating that the material was ready for pressing and injection pressure of 7 bar. By the end of the process the mould was allowed to cool for 35 minutes. The mould was then placed in water bath for 10 minutes then devesting was done first with scissors to remove the mould then using pneumatic devesting chisel. The fine blasting device was used to get the discs.

\section{Tooth brush simulation}

All the samples were stored in artificial saliva at $37^{\circ} \mathrm{C} \pm 1^{\circ} \mathrm{C}$ for 24 hours. The rehydration simulated the first day of service for restorations in the oral environment. Simulated tooth brushing for 4 min with rotary instruments (ROBOTA chewing simulator operated on servo-motor (Model ACH09075DC-T, AD-Tech Technology Co., Ltd., Germany) was performed using toothbrush heads with soft nylon bristles (Oral B Indicator; Procter \& Gamble Nanning, Kwangsi, China) under 300-gr load.

\section{Abrasive medium}

Slurry was prepared by mixing a $2: 1$ ratio of deionized water and a sodium fluoride $0.22 \% \mathrm{w} / \mathrm{w}$ (1000 ppm F) particle dentifrice (Colgate maxfresh; Colgate-Palmolive, Bangna-Trad, Amphur Muang, Chonburi, Thailand) immediately before brushing. 
After brushing, the samples were cleaned with running water followed by an ultrasonic bath for $10 \mathrm{~min}$.

\section{Preparation of the staining solutions}

Artificial saliva was prepared, and it consisted of the following ingredients: $1 \mathrm{~g}$ sodium carboxymethylcellulose, $4.3 \mathrm{~g}$ xylitol, $0.1 \mathrm{~g}$ potassium chloride, $5 \mathrm{mg}$ calcium chloride, $40 \mathrm{mg}$ potassium phosphate, $1 \mathrm{mg}$ potassium thiocyanate and $100 \mathrm{~g}$ deionized water. ${ }^{13}$ Each oral rinse (chlorhexidine, benzydamine $\mathrm{HCl}$, alcohol-free mouthwash) and the artificial saliva were maintained in a dark environment at $37^{\circ} \mathrm{C} \pm 1^{\circ} \mathrm{C}$ to stimulate the conditions in oral cavity. The staining solutions were changed twice a day throughout whole experimental time (one week).

\section{Evaluation of color change}

The color values $\left(\mathrm{L}^{*}, \mathrm{a}^{*}, \mathrm{~b}^{*}\right)$ of each samples were measured before exposure with a Reflective spectrophotometer (X-Rite, model RM200QC, Neu-Isenburg, Germany). The aperture size was set to $4 \mathrm{~mm}$ and the samples were exactly aligned with the device. A white background was selected, and measurements were made according to the CIE $\mathrm{L}^{*} \mathrm{a} * \mathrm{~b} *$ color space relative to the CIE standard illuminant D65. The CIE L*a*b* system is an approximately uniform color space with coordinates for lightness, namely white-black ( $\left.\mathrm{L}^{*}\right)$, redness-green $\left(a^{*}\right)$, and yellowness-blueness $\left(b^{*}\right)$. The measurements were repeated 3 times for each samples, and the mean values of $L^{*}, a^{*}, b^{*}$ were calculated. After the baseline color measurements were obtained, the samples were immersed into the staining solutions. After one week of immersion, the samples were rinsed with distilled water for 5 minutes and gently brushed with a soft toothbrush for 15 seconds. At this point, color measurements were recorded with the same spectrophotometer, and these measurements were performed under the same conditions and in the same manner described for the baseline measurements. The calculation of the color variation $\Delta \mathrm{E}^{*}$ between two color positions (one week of storage and baseline) in 3-dimensional $\mathrm{L}^{*} \mathrm{a} * \mathrm{~b} *$ color space is as follows:

$$
\Delta \mathrm{E}_{\text {CIELAB }}=\left(\Delta \mathrm{L}^{* 2}+\Delta \mathrm{a}^{* 2}+\Delta \mathrm{b}^{* 2}\right)^{1 / 2}
$$

Where: $\mathrm{L}=*$ lightness $(0-100), \mathrm{a}=*$ change the color of the axis (red/green) and $b=*$ color variation axis (yellow/blue).

\section{Statistical analysis}

The results were analyzed using Graph Pad Instat (Graph Pad, Inc.) software for windows. A value of $P \leq 0.05$ was considered statistically significant. Continuous variables were expressed as the mean and standard deviation. After homogeneity of variance and normal distribution of errors had been confirmed, two-way ANOVA was done to detect effect of each variable (materials groups and oral rinse staining solutions subgroups). One-way ANOVA followed by pair-wise Tukey's post-hoc tests were performed to detect significance between subgroups and main group. Student t-test was done for compared pairs. Sample size $(n=7)$ was large enough to detect large effect sizes for main effects and pair-wise comparisons, with the satisfactory level of power set at $80 \%$ and a $95 \%$ confidence level.

\section{RESULTS}

Color change $(\Delta \mathrm{E})$ results $(\mathrm{Mean} \pm \mathrm{SD})$ for both groups as function of oral rinse staining solutions are summarized in table (2) and figure (1).

Effect of material; regardless to staining solutions totally it was shown that Acetal Resin material group recorded higher color change mean value $(4.75 \pm 0.52 \Delta \mathrm{E})$ than PEEK material group mean value $(4.64 \pm 0.66 \Delta \mathrm{E})$. The difference between both materials groups means values was statistically non-significant as indicated by two-way ANOVA $(\mathrm{F}=0.31, \mathrm{P}=0.5748>0.05)$. 
Effect of oral rinse staining solution; the difference between A. saliva and staining solutions means values was statistically significant as indicated by two-way ANOVA ( $\mathrm{F}=3.4, \mathrm{P}=0.0244$ $<0.05)$. Pair-wise Tukey's post-hoc test showed non-significant $(p>0.05)$ difference between A. saliva and CHX solution.

\section{Interaction between variables}

With A. saliva solution; it was shown that PEEK material group recorded statistically non-significant higher color change mean value $(4.43 \pm 0.69 \Delta \mathrm{E})$ than Acetal Resin material group mean value $(4.16 \pm 0.48 \Delta \mathrm{E})$ as demonstrated by $\mathrm{t}$-test $(\mathrm{t}=0.74$, $\mathrm{P}=0.4732>0.05)$.

With CHX solution; also, it was shown that Acetal Resin material group recorded statistically non-significant higher color change mean value $(4.64 \pm 0.75 \Delta \mathrm{E})$ than PEEK material group mean value $(4.40 \pm 0.82 \Delta \mathrm{E})$ as demonstrated by t-test $(\mathrm{t}=0.5, \mathrm{P}=0.6287>0.05)$.

With Tantum $V$ solution; it was shown that Acetal Resin material group recorded statistically non-significant higher color change mean value $(5.02 \pm 0.55 \Delta \mathrm{E})$ than PEEK material group mean value $(4.79 \pm 0.26 \Delta \mathrm{E})$ as demonstrated by t-test $(\mathrm{t}=0.9, \mathrm{P}=0.3813>0.05)$.
With Listerine zero solution; it was shown that Acetal Resin material group recorded statistically non-significant higher color change mean value $(5.16 \pm 0.29 \Delta \mathrm{E})$ than PEEK material group mean value $(4.94 \pm 0.84 \Delta \mathrm{E})$ as demonstrated by t-test $(\mathrm{t}=0.6, \mathrm{P}=0.5788>0.05)$.

In Acetal resin materials group; it was shown that Listerine zero recorded the highest color change mean value $(5.16 \pm 0.29 \Delta \mathrm{E})$ followed by Tantum $\mathrm{V}$ solution mean value $(5.02 \pm 0.55 \Delta \mathrm{E})$ then $\mathrm{CHX}$ solution mean value $(4.64 \pm 0.75 \Delta \mathrm{E})$ while $\mathrm{A}$. saliva solution recorded the lowest color change mean value $(4.16 \pm 0.48 \Delta \mathrm{E})$. The difference between A. saliva and staining solutions means values was statistically significant as indicated by two-way ANOVA $(\mathrm{F}=3.9, \mathrm{P}=0.0243<0.05)$. Pair-wise Tukey's posthoc test showed non-significant $(\mathrm{p}>0.05)$ difference between A. saliva and $\mathrm{CHX}$ solution

In PEEK materials group; it was shown that Listerine zero recorded the highest color change mean value $(4.94 \pm 0.84 \Delta \mathrm{E})$ followed by Tantum $\mathrm{V}$ solution mean value $(4.79 \pm 0.26 \Delta \mathrm{E})$ then $\mathrm{A}$. saliva solution mean value $(4.43 \pm 0.69 \Delta \mathrm{E})$ while CHX solution recorded the lowest color change mean value $(4.40 \pm 0.82 \quad \Delta \mathrm{E})$. The difference between solutions means values was statistically non-significant as indicated by two-way ANOVA $(\mathrm{F}=0.96, \mathrm{P}=0.4305>0.05)$.

TABLE (2) Color change $(\Delta \mathrm{E})$ results $(\mathrm{Mean} \pm \mathrm{SD})$ for both groups as function of oral rinse staining solutions

\begin{tabular}{|c|c|c|c|c|c|c|c|c|}
\hline \multirow{2}{*}{ Variables } & \multicolumn{4}{|c|}{ Acetal Resin } & \multicolumn{4}{|c|}{ PEEK } \\
\hline & $\Delta \mathrm{L}$ & $\Delta \mathrm{a}$ & $\Delta b$ & $\Delta \mathrm{E}$ & $\Delta \mathrm{L}$ & $\Delta \mathrm{a}$ & $\Delta \mathrm{b}$ & $\Delta \mathrm{E}$ \\
\hline A. saliva & -3.97 & -0.47 & -1.07 & $4.16^{\mathrm{A}} \pm 0.48$ & 1.43 & -2.37 & -1.27 & $4.43^{\mathrm{A}} \pm 0.69$ \\
\hline CHX & 3.77 & 1.13 & 0.27 & $4.64^{\mathrm{A}} \pm 0.75$ & 1.70 & -1.03 & 3.57 & $4.40^{\mathrm{A}} \pm 0.82$ \\
\hline Tantum $V$ & -4.97 & -0.03 & 0.63 & $5.02^{\mathrm{A}} \pm 0.55$ & -0.90 & -0.30 & -2.83 & $4.79^{\mathrm{A}}{ }_{\mathrm{a}} \pm 0.26$ \\
\hline Listerine zero & 3.33 & 1.00 & 3.80 & $5.16^{\mathrm{A}} \pm 0.29$ & 2.07 & -0.63 & -1.77 & $4.94^{\mathrm{A}}{ }_{\mathrm{a}} \pm 0.84$ \\
\hline Total & -0.46 & 0.41 & 0.91 & $4.75^{\mathrm{A}} \pm 0.52$ & 1.08 & -1.08 & -0.58 & $4.64^{\mathrm{A}} \pm 0.66$ \\
\hline P value & \multicolumn{4}{|c|}{$0.0243 *$} & \multicolumn{4}{|c|}{$<0.0001 *$} \\
\hline
\end{tabular}

Different superscript large letter in same row indicating significant between materials (Tukey's p<0.05) Different subscript small letter in same column indicating significant between solutions (Tukey's $p<0.05)$

*; significant $(p<0.05) n s ;$ non-significant $(p>0.05)$ 


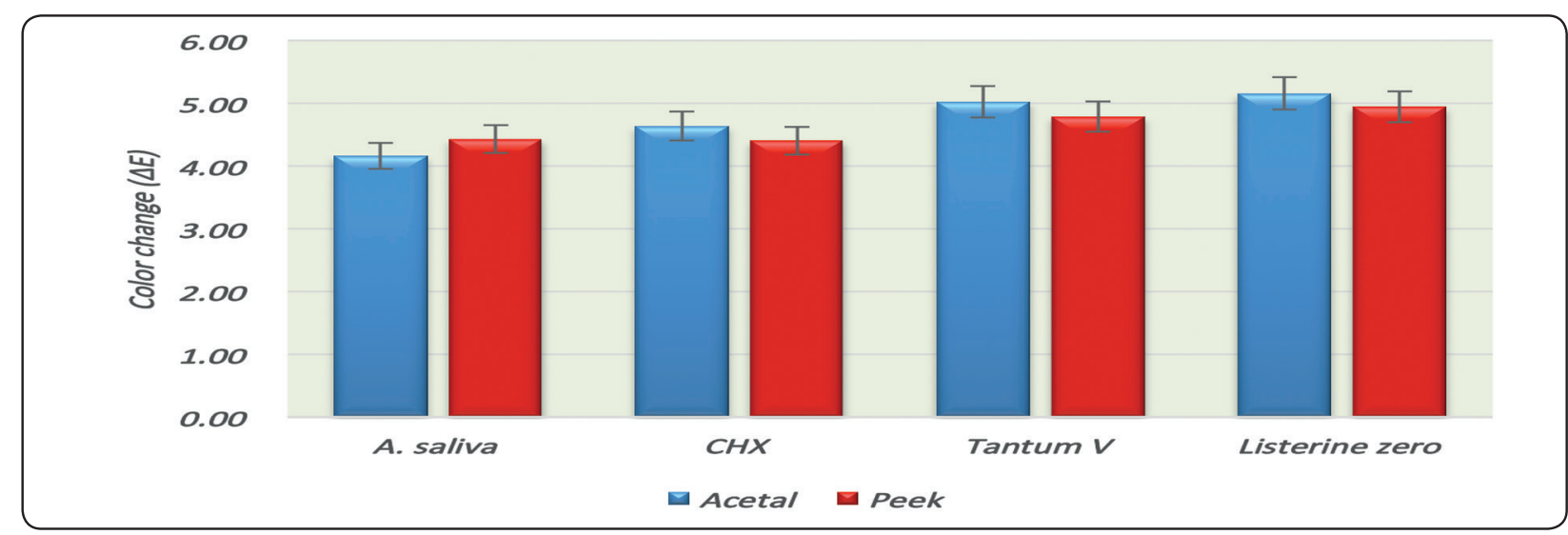

Fig. (1) Column chart of the mean values of color change for both groups as function of oral rinse staining solutions

\section{DISCUSSION}

Color of dental restorative material is one of the optical properties, and it is the visual perception of an object, or substance regarding the light reflected, or transmitted through. ${ }^{14}$ Tooth-colored fillings and natural dental prostheses are important expectations to achieve patients and dentists satisfaction.

The degree of color stability can be affected by many factors such as: incomplete polymerization, chemical reactivity, water sorption, and surface roughness of material. ${ }^{10,11}$ Polishing ability and material structure not the only parameters providing color stability for a longer period of time but also patient's dietary habits and cleaning measures are key factors. ${ }^{15,16}$

Acetal resin or POM has been introduced in the dental market as an esthetic, thermoplastic material possess good short-term mechanical properties, but as a co-polymer has better long term stability, ${ }^{17}$ owing to its crystalline structure which improves the material strength and wear resistance. Curing process through injection molding technique allows better internal adaptation if compared with conventional heat cured and microwave polymerized resins. ${ }^{18,19}$

Available 20 different color shades of acetal;17 of which are comparable with Vita-pan shade guide scale and 3 pink, enables its use as a successful denture base material and tooth- colored clasps especially in larger retentive undercuts than recommended for Cobalt- Chromium alloys due to its low modulus of elasticity (2.9 to $3.5 \mathrm{kN} / \mathrm{mm} 2){ }^{4,5}$ This may be advantageous in clinical situations where esthetics and/or periodontal health are extremely important.$^{20}$ Additionally, its usage as stress absorbing action elements, provisional restorations and splints, ${ }^{17,19,21-24}$ proving to be the "Gen- X material in esthetic restorative dentistry".

Polyetheretherketone (PEEK) is another semicrystalline thermoplastic polymer and is considered as a promising alternative in fixed and removable prosthetic dentistry with observed mechanical properties ${ }^{25}$ and adequate mechanical stability to fulfill the basic requirements in the restorative field as showed by recent studies. ${ }^{26,27}$ For advanced PEEK based materials Behr ${ }^{28}$ reported great fracture resistance of fixed dental prosthesis exceeding that required to withstand forces assumed for anterior $(300 \mathrm{~N})$ and posterior region $(500-600 \mathrm{~N})$.

Additionaly, biocompatibility and low elastic modulus $(3.6 \mathrm{GPa})^{29}$ of PEEK that could be modified by reinforcing it with carbon fibers, for example in order to simulate that of cortical bone $(18 \mathrm{GPa}),{ }^{30}$ made it possible to be offered commercially as a titanium substitute for dental endosseous implants. Regarding esthetics, biocompatibility and light 
weight, another important application of PEEK in prosthodontics was also reported by Zoidis ${ }^{9}$ as an alternative framework material for removable partial dentures.

Discoloration of dental prostheses and restorations is attributed to either ${ }^{31,32}$ : intrinsic factors related to heredity, age, and processing modes of these restorations, ${ }^{33}$ or extrinsic factors derived mainly from colorants of food products such as caffeinecontaining beverages or mouth rinses,$^{34}$ which in turn adhere on restoration surfaces by ${ }^{35}$ : physical and chemical electrostatic forces (van der Waals) and hydrophobic interdigitation.

Such color changes can be evaluated by visual perception or preferably by instrumental techniques like spectrophotometer since it eliminate the subjective interpretation, ${ }^{36}$ and the risk of manual errors ${ }^{37-39}$ as it stores and transforms data into a spreadsheet for statistical analysis by special software.

Hence spectrophotometer was used in this study to measure the total color change ( $\Delta \mathrm{E}$ ) of the three axes: $L^{*}, a^{*}$, and $b^{*}$ for two thermoplastic materials (acetal and PEEK) at base line and one week after immersion in three different oral rinses compared to artificial saliva. In order to accurately reflect clinical conditions of personal cleaning procedures, the specimens were subjected to simulated tooth brushing for $4 \mathrm{~min}$ with rotary instruments before immersion in oral rinses.

According to the results of the present study regarding the restoration materials tested, the null hypothesis was accepted. Although acetal recorded higher color change, there was satistically no significant difference in color change mean value of acetal $(4.75 \pm 0.52 \Delta \mathrm{E})$ and that of PEEK material group $(4.64 \pm 0.66 \Delta \mathrm{E})$. Since color stability significantly depends on surface roughness and surface free energy, ${ }^{40}$ also several studies showed that there is a positive correlation between high surface roughness and discoloration of restorative materials, ${ }^{41,42}$ the present results could be attributed to approximated surface roughness and grain size of acetal 110-150 gm and that of PEEK 80grn which is considered slightly more fine and smoother. ${ }^{43}$

In addition relatively close manufacturing techniques that permit accurate adaptation of the material in its mould would probably affect the final density, porosity and hence roughness of the restoration. ${ }^{44}$ Also standardization of finishing and polishing procedures and instruments would seem to produce a smooth surface, and play crucial role in reducing pigmentations. ${ }^{45} \mathrm{On}$ the other hand, being semi-crystalline, both acetal and PEEK could have similar degrees of pigmentation since degree of crystallinity, is one of the important factors affecting the ability of the materials for water or staining solution sorption. ${ }^{46,47}$

Relative color change results of both acetal and PEEK in this study were inclusively supported in researches by almost good color stability of each material. Heimer ${ }^{48}$ concluded that PEEK showed the significantly lowest discoloration after a 1-week storage over all coloring media; red wine, curry, and chlorhexidine as compared to PMMA and COMP. Tannous ${ }^{49}$ and hallmann ${ }^{50}$ confirmed that PEEK as an attractive prosthodontic material have a reduced degree of discoloration. Also acetal resin, results of Ozcan et $\mathbf{a l}^{51}$ reseach showed clinically acceptable color changes of acetal after 300 hours of thermocycling.

In the present study, according to the results regarding oral rinses and artificial saliva, the null hypothesis was partially rejected. Although there was non significant difference in color change potential of oral rinses and artificial salive on PEEK, statistically significant difference of their staining potential was recorded with acetal resin; Listerine zero recorded the highest color change mean value $(5.16 \pm 0.29 \Delta \mathrm{E})$ followed by Tantum $\mathrm{V}$ solution mean value $(5.02 \pm 0.55 \Delta \mathrm{E})$ then $\mathrm{CHX}$ solution mean value $(4.64 \pm 0.75 \Delta \mathrm{E})$ while $\mathrm{A}$. saliva solution recorded the lowest mean value $(4.16 \pm 0.48 \Delta \mathrm{E})$ of color change. 
This could be justified by the susceptibility of the acetal resin to water sorption, with subsequent hydrolysis that might alter the original color of the tested material. ${ }^{47,52}$ This water sorption is important sign since if the resinous material is capable of absorbing water, it can also absorb other fluids. ${ }^{53}$

Therefore, regarding listerine zero Gürgan et al ${ }^{54}$ showed that irrespective of alcohol concentration, both alcohol-containing and alcohol-free mouth rinses could affect the hardness of resin-restorative materials. also composite resin discoloration has been reported following the use of Listerine ${ }^{\circledR}$ mouth rinse..$^{55}$

Composition and coloring material incorporated in the mouth rinses may be another possible reasons for the increased color differences $\left(\Delta \mathrm{E}^{*}\right)$ values caused by such solutions, so the color change of Benzydamine hydrochloride used in this study may be attributed to the type of colorant; quinoline yellow used in the mouth rinse. Thus, according to polarity variations of coloring constituents, the staining potential for each solution could be determined. This was supported by Ruyter et al. ${ }^{56}$ who have reported that constituents of tea that have high polarity are released first and adsorbed onto the material surface followed by those with lower polarity in coffee.

With regard to staining effect of CHX in the present study, it was in accordance to research which has been reported discoloration of restorative materials following their immersion in $\mathrm{CHX}$ mouth rinse. ${ }^{57,58}$ More over CHX has been found to induce brown stains on enamel, composite restorations, oral mucosa, and tongue. ${ }^{59-61}$ Three mechanisms have been suggested to explain this discoloration: ${ }^{62,63} \mathrm{~A}$. non-enzymatic browning reactions (Maillard reactions), B. formation of pigmented (Fe, Sn)sulphides, and C. reaction of dietary chromogens with CHX.

\section{CONCLUSIONS}

1- There was a highly significant difference between alcohol free, benzydamine HCL \& CHX mouth rinses. The listerine zero showed the highest value in staining potential while $\mathrm{CHX}$ was the lowest regarding acetal

2- Among the two thermoplastic restorative materials and although statisticaly non significant, PEEK was found to be the higher color stable material and the higher stain was taken up by acetal resin.

3- There were no significant differences between the discoloration effects of different mouth washes used in this study on PEEK material.

\section{REFERENCES}

1. Dietschi, D. Optimizing smile composition and esthetics with resin composites and other conservative esthetic procedures. Eur. J. Esthet. Dent. 2008; 3: 14-29.

2. Pjetursson, B.E.; Asgeirsson, A.G.; Zwahlen, M.; Sailer, I. Improvements in implant dentistry over the last decade: Comparison of survival and complication rates in older and newer publications. Int. J. Oral Maxillofac. Implants 2014; 29: 308-324.

3. Kopperud, S.E.; Tveit, A.B.; Gaarden, T.; Sandvik, L.; Espelid, I. Longevity of posterior dental restorations and reasons for failure. Eur. J. Oral Sci. 2012; 120: 539-548.

4. Fitton JS, Davies EH, Homlett JA et al. The physical properties of a polyacetal denture resin. Clin Mater 1995; 17:125-129.

5. Kirsch A, Ackerman KL. The IMZ osseo integrated implant system. Dent Clin. North. Am., 1989; 33:733-91.

6. Smith DC. Recent developments and prospects in dental polymers. J Prosthet Dent 1962; 12:1066-78.

7. Najeeb S, Zafar MS, Khurshid Z, Siddiqui F. Applications of polyetheretherketone (PEEK) in oral implantology and prosthodontics. J Prosthodont Res 2016;60:12-9.

8. Vaezi M, Yang S. A novel bioactive PEEK/HA composite with controlled 3D interconnected HA network. Int J Bioprint 2015;1:66-76.

9. Zoidis P, Papathanasiou I, Polyzois G. The Use of a modifi ed poly ether ether ketone (PEEK) as an alternative framework material for removable dental prostheses. A clinical report. J Prosthet Dent 2015;25:580-84. 
10. Pipko DJ, El-Sadeek M. An in vitro investigation of abrasion and staining of dental resin. J Dent Res.1972; 51:689-705

11. Hachiya Y, Hosoda H, Fusamaya Y. Relation of finish to discoloration of composite resin. J Prosthet Dent.1984; 52:811-814.

12. Özarslan MM, Büyükkaplan UŞ, Barutcigil Ç, Arslan M, Türker N, BarutcigilK. Effects of different surface finishing procedures on the change in surface roughness and color of a polymer infiltrated ceramic network material. J Adv Prosthodont.2016; 8:16-20.

13. Yumiko HY, Watanabe E, Tadokoro K, Inoue T, Miyazaki M, Franklin R. Effects of ammonium hexafluorosilicate application on demineralized enamel and dentin of primary teeth. Oral Sci. 2012; 54:267-272.

14. Academy of prosthodontic. Glossary of prosthodontic terms. J Prosthet Dental.2005; 94:24, 77.

15. Bagheri R, Burrow MF, Tyas M. Influence of food simulating solutions and surface finish on susceptibility to staining of aesthetic restorative materials. J Dent.2005; 33:389-398

16. Reis AF, Giannini M, Lovadino JR, Ambrosano GM. Effects of various finishing systems on the surface roughness and staining susceptibility of packable composite resins. Dent Mater.2003; 19:12-18

17. Thomas SA, Nandini VV. Acetal resin -A quantum leap in aesthetic restorative dentistry. IJCDS.2011; 4: 56-59.

18. Ganzarolli AM, De Mello JA, Shinkai RS, Del Bel Cury AA. Internal adaptation and physical properties of methacrylate-based denture resins polymerized by different techniques. J Biomed Mater Res B Appl Biomater.: 2007;82:169-173.

19. Arda T, ArikanA.:An in vitro comparison of the retentive force and deformation of acetal resin and cobalt chromium clasps, J Prosthet Dent.2005;94: 267-274.

20. Rodrigues RC, Ribeiro RF, Bezzon OL. Comparative study of circumferential clasp retention force for titanium and cobalt- chromium removable partial dentures. J Prosthet Dent 2002;88:290-6.

21. Turner JW, Radford DR, Sherriff M. Flexural properties and surface finishing of acetal resin denture clasps. J Prosthodont.1999; 8:188-95.

22. Phoenix RD, Mansueto MA, Ackerman NA, Jones RE. Evaluation of mechanical and thermal properties of commonly used denture base resins. J Prosthodont.2004; 13:17-27.

23. Lekha K, Savitha NP, Roseline M, Nadigar RK. Acetal resin as an aesthetic clasp material. J Interdiscip Dent.2011; 2:11-14.
24. Gasser B, Misteli G, Mathys RJ. Biocompatibility of polyoxymethylene (Derlin) in bone. Biomater.1993; 14:1188-9.

25. Stawarczyk, B.; Beuer, F.;Wimmer, T.; Jahn, D.; Sener, B.; Roos, M.; Schmidlin, P.R. Polyetheretherketone-a suitable material for fixed dental prostheses? J. Biomed. Mater. Res. Part B Appl. Biomater. 2013; 101:1209-1216.

26. Stawarczyk, B.; Jordan, P.; Schmidlin, P.R.; Roos, M.; Eichberger, M.; Gernet, W.; Keul, C. PEEK surface treatment effects on tensile bond strength to veneering resins. J. Prosthet. Dent. 2014; 112: 1278-1288.

27. Uhrenbacher, J.; Schmidlin, P.R.; Keul, C.; Eichberger, M.; Roos, M.; Gernet, W.; Stawarczyk, B. The effect of surface modification on the retention strength of polyetheretherketone crowns adhesively bonded to dentin abutments. J. Prosthet. Dent. 2014; 112: 1489-1497.

28. Behr. Clinical oral implants research 12;174-178

29. Moon SM, Ingalhalikar A, Highsmith JM, Vaccaro AR. Biomechanical rigidity of an all-polyetheretherketone anterior thoracolumbar spinal reconstruction construct: an in vitro corpectomy model. Spine J. 2009;9:330-335.

30. Skinner HB. Composite technology for total hip arthroplasty. Clin Orthop Relat Res. 1988;235:224-236.

31. Kumari RV, Nagaraj H, Siddaraju K, Poluri RK. Evaluation of the effect of surface polishing, oral beverages and food colorants on color stability and surface roughness of nanocomposite resins. J Int Oral Health.2015; 7:63-70

32. Hattab FN, Qudeimat MA, Al-Rimawi HS. Dental discoloration: an overview. J Esthet Dent.1999; 11:291-310.

33. Cengiz S, Yüzbaşioğlu E, Cengiz MI, Velioğlu N, Sevimli G. Color stability and surface roughness of a laboratoryprocessed composite resin as a function of mouth rinse. $\mathrm{J}$ Esthet Restor Dent.2015; 27:314-321

34. Addy M, Mahdavi SA, Loyn T. Dietary staining in vitro by mouthrinses as a comparative measure of antiseptic activity and predictor of staining in vivo. J Dent.1995; 23:95-99

35. Nathoo SA. The chemistry and mechanisms of extrinsic and intrinsic discoloration. J Am Dent Assoc.1997; 128(Suppl):6S-10S.

36. Um CM, Ruyter IE. Staining of resin-based veneering materials with coffee and tea. Quintessence Int.1991; 22: 377-386.

37. Joiner A. Tooth color: a review of the literature. J Dent. 2004; 32: 3-12.

38. Buyukyılmaz S, Ruyter IE. Color stability of denture base polymers. Int J Prosthodont.1994; 7: 372-382. 
39. Guler AU, Yilmaz F, Kulunk T, Guler E, Kurt S. Effects of different drinks on stainability of resin composite provisional restorative materials. J Prosthet Dent.2005; 94:118-24.

40. Gönülol N, Yilmaz F. The effects of finishing and polishing techniques on surface roughness and color stability of nanocomposites. J Dent.2012; 40s:e64-e70

41. Türkün LS, Leblebicioglu EA. Stain retention and surface characteristics of posterior composites polished by onestep systems. Am J Dent.2006; 19:343-347.

42. Yap AU, Lye KW, Sau CW. Surface characteristics of tooth colored restoratives polished utilizing different polishing systems. Oper Dent1997; 22:260-265.

43. Alfredo Campo E. Selection of polymeric materials. Full Ed.NY, USA William Andrew Inc; 2008 ; 23-37

44. Parvizi A. Lindquist T. Schneider R. Williamson D. Boyer D. Dawson DV: Comparison of the dimensional accuracy of injection-molded denture base materials to that of conventional pressure-pack acrylic resin. J. Prosthodont. 2004;13:83-89.

45. Scotti R, Mascellani Sc and Foruiti F: The In Vitro Color Stability of Acrylic Resin for Provisional Restorations. Int Prosthodont 1997; 10 (2): 164-168.

46. Al Kheraif A-A A-A, Bin Qasim SS, Ramakrishnaiah R, Rehman I. Effect of different beverages on the color stability and degree of conversion of nano and microhybrid composites. J Dent Mater. 2013; 32: 326-33.

47. Arikan A, Ozkan YK, Arda T, Akalin B. An in vitro investigation of water sorption and solubility of two acetal denture base materials. Eur J Prosthodont Restor Dent.2005; 13:119-22.

48. Sina Heimer \& Patrick R. Schmidlin2 \& Bogna Stawarczyk. Discoloration of PMMA, composite, and PEEK. Clin Oral Invest. 2016;6:1892-6.

49. Tannous F, Steiner M, Shahin R, Kern M. Retentive forces and fatigue resistance of thermoplastic resin clasps. Dent Mater 2012;28:273-8

50. Hallmann L, Mehl A, Sereno N, Hämmerle CH. The improvement of adhesive properties of PEEK through different pre-treatments. Appl Surf Sci 2012;258;7213-8.

51. Ozkan Y, Arikan A, Akalin B, Arda T. A study to assess the color stability of acetal resins subjected to thermocycling. Eur. J. Prosthodont. Rest. Dent., 2005;13(1):10-14.
52. Arıkan A, Ozkan YK, Arda T, Akalın B. Effect of 180 days of water storage on the transverse strength of acetal resin denture base material. J Prosthodont 2010;19: 47-51.

53. Mundim FM, Garcia LFR, Pires-De-Souza FCP. Effect of staining solutions and repolishing on color stability of direct composites. J Appl Oral Sci.2010; 18: 249-254.

54. Gürgan S, Önen A, Köprülü H. In vitro effects of alcohol containing and alcohol-free mouth rinses on micro hardness of some restorative materials. J Oral Rehabil 1997;24:244- 246.

55. ElEmbaby Ael-S. The effects of mouth rinses on the color stability of resin-based restorative materials. J Esthet Restor Dent. 2014;26:264-71.

56. Ruyter IE, Oysaed H. Analysis and characterization of dental polymers. Crit Rev Biocompat.1988; 4: 3: 247-279.

57. Mutlu-Sagesen L, Ergün G, Ozkan Y, Semiz M. Color stability of a dental composite after immersion in various media. Dent Mater J. 2005;24:382-90.

58. Falkensammer F, Arnetzl GV, Wildburger A, Freudenthaler J. Color stability of different composite resin materials. J Prosthet Dent. 2013;109:378-83.

59. Sheen S, Owens J, Addy M. The effect of toothpaste on the propensity of chlorhexidine and cetyl pyridinium chloride to produce staining in vitro: a possible predictor of inactivation. J Clin Periodontol. 2001;28:46-51. [PubMed]

60. Lorenz K, Bruhn G, Heumann C, Netuschil L, Brecx M, Hoffmann T. Effect of two new chlorhexidine mouthrinses on the development of dental plaque, gingivitis, and discolouration. A randomized, investigator-blind, placebocontrolled, 3-week experimental gingivitis study. J Clin Periodontol. 2006;33:561-7.

61. Zanatta FB, Antoniazzi RP, Rösing CK. Staining and calculus formation after $0.12 \%$ chlorhexidine rinses in plaque-free and plaque covered surfaces: a randomized trial. J Appl Oral Sci. 2010;18:515-21.

62. Ellingsen JE, Rolla G, Eriksen HM. Extrinsic dental stain caused by chlorhexidine and other denaturing agents. J Clin Periodontol. 1982;9:317-22.

63. Eriksen HM, Nordbo H, Kantanen H, Ellingsen JE. Chemical plaque control and extrinsic tooth discoloration. A review of possible mechanisms. J Clin Periodontol. 1985;12:345-50. 